\title{
Research Square \\ Optimality principles explaining divergent responses of alpine vegetation to environmental change
}

\section{Ziqi Zhu}

Tsinghua University

Han Wang ( $\Delta$ wang_han@mail.tsinghua.edu.cn )

Tsinghua University

\section{Sandy Harrison}

University of Reading https://orcid.org/0000-0001-5687-1903

lain Prentice

Imperial College London https://orcid.org/0000-0002-1296-6764

\section{Shengchao Qiao}

Tsinghua University

Shen Tan

Tsinghua University

\section{Article}

Keywords:

Posted Date: January 18th, 2022

DOI: https://doi.org/10.21203/rs.3.rs-1209202/v1

License: (1) This work is licensed under a Creative Commons Attribution 4.0 International License. Read Full License 
1 Optimality principles explaining divergent responses of alpine vegetation to environmental change

Ziqi Zhu ${ }^{1}$, Han Wang ${ }^{1, *}$, Sandy P. Harrison ${ }^{1,2}$, I. Colin Prentice ${ }^{1,3,4}$, Shengchao Qiao ${ }^{1}$, Shen Tan ${ }^{1}$

1 Department of Earth System Science, Ministry of Education Key Laboratory for Earth System Modeling, Institute for Global Change Studies, Tsinghua University, Beijing 100084, China 2 School of Archaeology, Geography and Environmental Sciences (SAGES), University of Reading, Reading RG6 6AH, United Kingdom

103 Department of Life Sciences, Imperial College London, Silwood Park Campus, Buckhurst Road, 11 Ascot SL5 7PY, United Kingdom

124 Department of Biological Sciences, Macquarie University, North Ryde, NSW 2109, Australia 13

Abstract: Recent increases in vegetation cover, observed over much of the world, reflect increasing $\mathrm{CO}_{2}$ globally and warming in cold areas. However, the strength of the response to both $\mathrm{CO}_{2}$ and warming appears to be declining. Here we examine changes in vegetation cover on the Tibetan Plateau over the past 35 years. Although the climate trends are similar across the Plateau, drier regions have become greener by $0.31 \pm 0.14 \% \mathrm{yr}^{-1}$ while wetter regions have become browner by $0.12 \pm 0.08 \%$ $\mathrm{yr}^{-1}$. This divergent response is predicted by a universal model of primary production accounting for optimal carbon allocation to leaves, subject to constraint by water availability. Rising $\mathrm{CO}_{2}$ stimulates production in both greening and browning areas; increased precipitation enhances growth in dry regions, but growth is reduced in wetter regions because warming increases below-ground allocation costs. The declining sensitivity of vegetation to climate change reflects a shift from water to energy limitation.

\section{Main text}

A global increase in vegetation cover has been observed in recent decades ${ }^{1-3}$ although this greening is not universal and some regions have experienced browning ${ }^{4,5}$. Greening has been attributed to human activities ${ }^{1,2,6}$. Recent increases in atmospheric $\mathrm{CO}_{2}$ concentration have had a positive impact on primary production and enhanced vegetation $\operatorname{cover}^{7-9}$. The impact of changes in climate has been more spatially heterogeneous ${ }^{2,3}$ but it is thought that warming explains the marked greening trend observed in high northern latitudes ${ }^{10-12}$. There has been a $16 \%$ decline in the area of the northern extratropics where vegetation growth is limited by temperature over the past three decades, primarily at the southern margin of high-latitude ecosystems ${ }^{10}$. However, there is evidence that the thermal response of vegetation growth and carbon uptake has weakened over this period ${ }^{13,14}$ for reasons that 
36 are still unclear, imposing large uncertainties on vegetation responses to future warming and vegetation feedbacks to the carbon cycle.

Most analysis of vegetation responses to temperature has focused on the high northern latitudes ${ }^{11,13,14}$.

The Tibetan Plateau, known as the "third pole" ${ }^{, 15}$, has experienced rapid warming ${ }^{16,17}$ with an increase of $0.35^{\circ} \mathrm{C}$ decade $^{-1}$ since $1970^{18}$. The increase in temperature over the Plateau is higher than the global mean warming, and comparable to that seen in the Arctic ${ }^{18}$. The impact of environmental change on the vegetation of this region has not been extensively studied ${ }^{19,20}$, despite the fact that it provides an opportunity to examine whether the positive response of vegetation to warming in cold regions is universal.

We have used remotely sensed maximum absorbed photosynthetically active radiation $\left(F_{\max }\right)$ as a measure of changes in peak vegetation cover ${ }^{6,21}$ and compared these trends to changes in climate and environmental factors. We developed a parsimonious model that simulates primary production using an optimality-based approach to account for carbon allocation to leaves subject to constraint by water availability (see Methods). We used this model to quantify the individual contributions of changes in precipitation, $\mathrm{CO}_{2}$ concentration, radiation, vapour pressure deficit and temperature to the observed trends in vegetation growth across the Tibetan Plateau and to examine the cause of the observed decline in the sensitivity of vegetation growth to climate in recent decades. We show that both the observed vegetation changes on the Tibetan Plateau and the observed changes in sensitivity to climate change can be explained by this simple model that invokes limitations on vegetation growth by water or energy availability.

\section{Results}

60 The climate of the Tibetan Plateau changed significantly between 1982 and 2016. Annual total

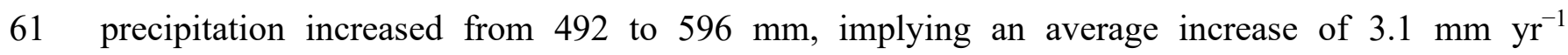
62 (Supplementary Fig. 1a). The largest increases in precipitation occurred in the driest areas. Those relatively small areas of the Plateau with high precipitation experienced a slight decrease (Supplementary Figs 2a, 3a and 4). Summer temperature, as measured by the accumulated

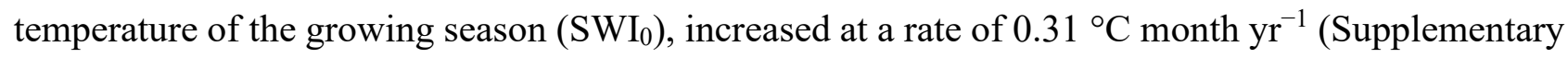

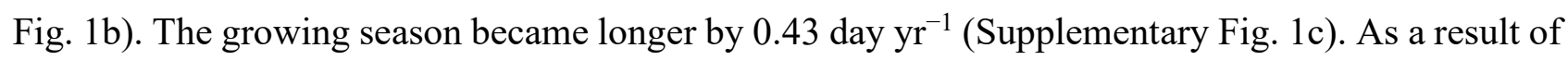
the extended growing season, incident solar radiation as measured by accumulated photosynthetic photon flux density (PPFD) during the growing season increased by $20.3 \mathrm{~mol} \mathrm{~m}^{-1} \mathrm{yr}^{-1}$

69 (Supplementary Fig. 1d). Although precipitation increased, atmospheric water demand as measured 
by vapour pressure deficit (VPD) increased by $0.0018 \mathrm{kPa} \mathrm{yr}^{-1}$ (Supplementary Fig. 1e). The trends in $\mathrm{SWI}_{0}$, PPFD and VPD are not spatially uniform, but they changed in the same direction across the whole of the region (Supplementary Figs 2 and 3). Atmospheric $\mathrm{CO}_{2}$ concentration, which is the principal driver of the changes in climate but has additional effects on plant physiology and growth, increased from 341 ppm in 1982 to 404 ppm in 2016 (Supplementary Fig. 1f).

Although climate, radiation and $\mathrm{CO}_{2}$ have changed in the same direction, the change in $F_{\max }$ across the Tibetan Plateau has not been uniform (Fig. 1a). About half (53\%) of the area has experienced greening and about half (47\%) browning between 1982 and 2016. The greening trend is most pronounced in the northwest, with a significant increase over $19 \%$ of the Plateau. Browning is more pronounced in the central and south-eastern parts of the Plateau and is significant over $15 \%$ of the area. In the climate space defined by annual total precipitation and $\mathrm{SWI}_{0}$, we found that the rapid increase in peak vegetation occurred in areas with low annual precipitation $(<500 \mathrm{~mm})$ while browning occurred in areas with high precipitation $(>500 \mathrm{~mm})$ (Fig. 1b).

a
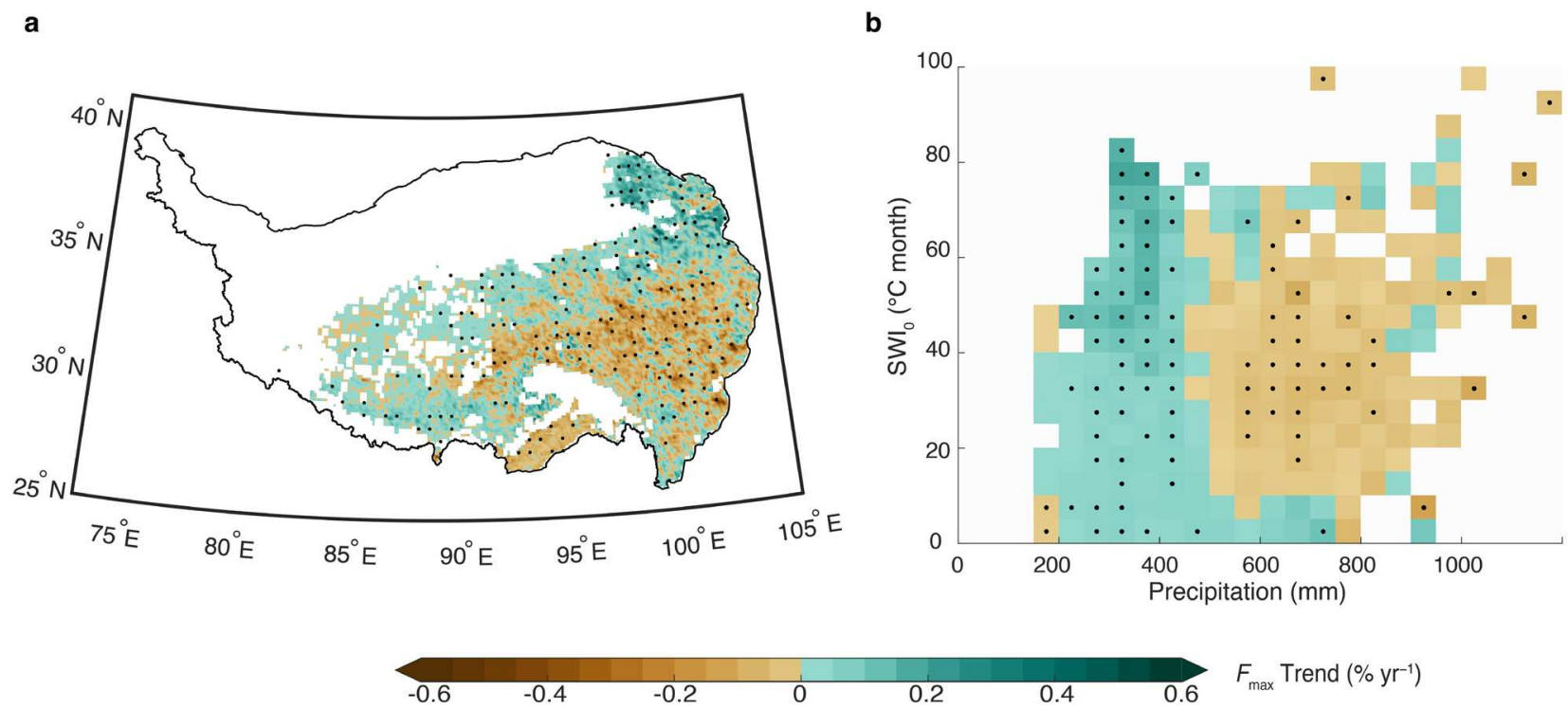

Fig. 1 | Divergent responses of alpine peak vegetation cover to environmental change. a, Spatial distribution of the temporal trend of GIMMS maximum fAPAR $\left(F_{\max }\right)$ over 1982-2016. $\mathbf{b}$, Trend of GIMMS $F_{\max }$ in the climate space of summer warmth index $\left(\mathrm{SWI}_{0}\right)$ and annual total precipitation. The climate space is subdivided into different bins of equal intervals with bin widths arbitrarily set to $5{ }^{\circ} \mathrm{C}$ month for $\mathrm{SWI}_{0}$ and $50 \mathrm{~mm}$ for precipitation. Trends for each bin are calculated by averaging the subset of all pixels falling within that bin. Bins containing less than 5 pixels are not included. Grid cells and climate bins labelled black dots indicate that the trends are statistically significant $(P<0.05)$. 
$F_{\text {max }}$ shows a strong relationship with both precipitation and temperature, with low values in drier and colder areas and high values in wetter and warmer areas. These two climate factors together explained $67 \%$ of the spatial variation in $F_{\max }$ (Fig. 2a). Log-sum-exp regression (see Methods) shows that $F_{\max }$ increased approximately linearly with precipitation and temperature when water and heat supply are insufficient (that is, in low precipitation and temperature conditions). $F_{\max }$ is even more closely related to precipitation and potential gross primary production $\left(A_{0}\right)$ as calculated by the $\mathrm{P}$ model (see Methods), with low $F_{\max }$ values in drier and low-energy supply areas and high values in wetter and high-energy supply areas (Fig. 2b). These two variables together account for around $75 \%$ of the spatial variation in $F_{\max }$, reflecting the fact that potential gross primary production integrates the effects of $\mathrm{SWI}_{0}$, PPDF and VPD on vegetation growth. This empirical analysis suggests that plant growth on the Tibetan Plateau may be limited by either water availability or energy availability, where water limited areas are mainly located in the northwest of the Plateau and energy limited areas in the centre and southeast (Supplementary Fig. 6).

a

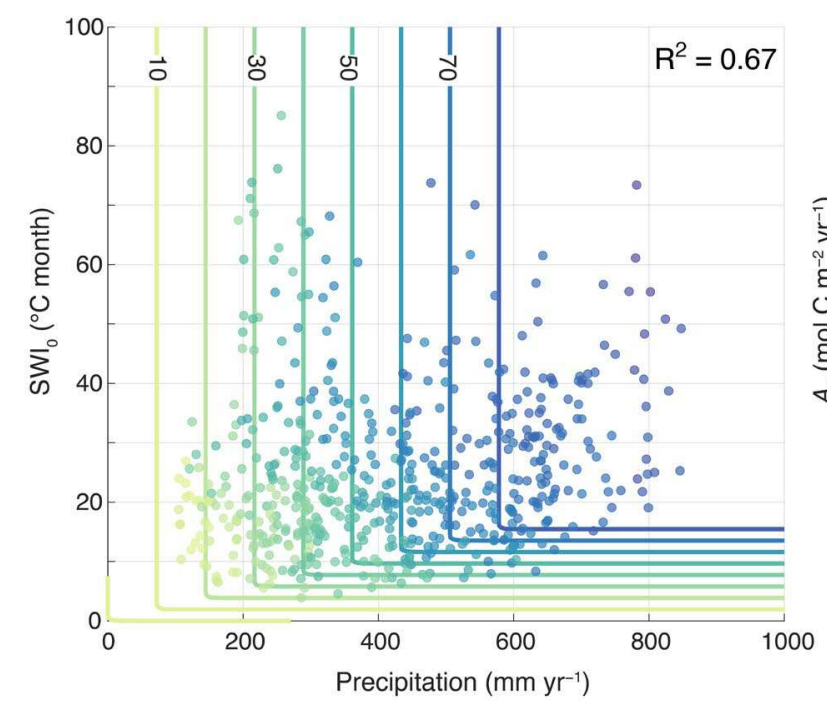

b

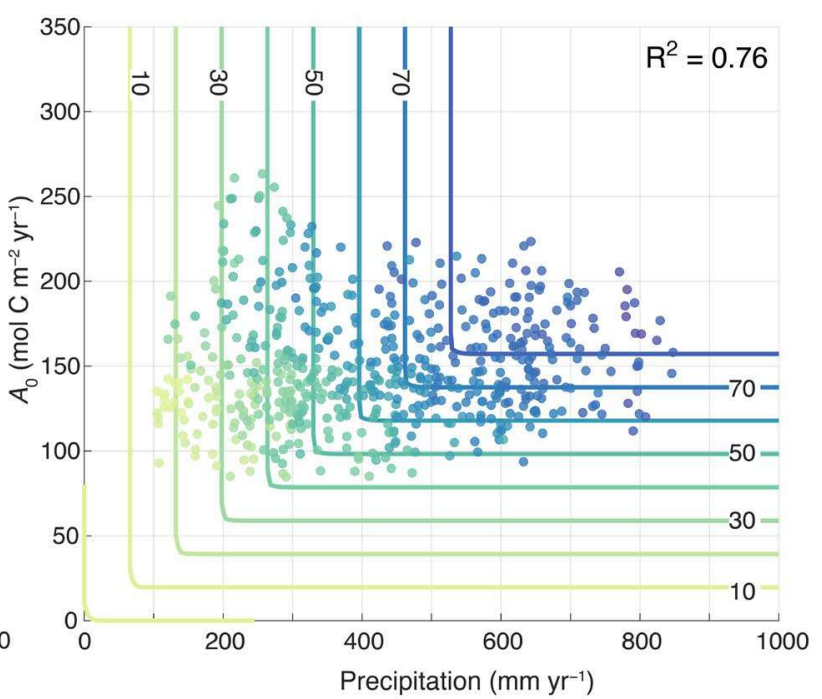

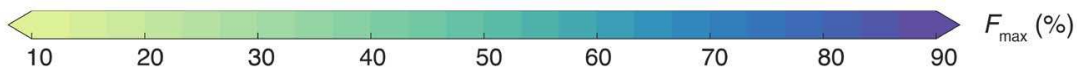

107 Fig. 2 | Relationship between peak vegetation growth and climate. a, Relationship between $F_{\max }$ and total 108 precipitation and summer warmth index $\left(\mathrm{SWI}_{0}\right)$ in 1982 . b, Relationship between $F_{\max }$ and total precipitation and potential gross primary production $\left(A_{0}\right)$ in $1982 . F_{\max }$ selected in each $50 \mathrm{~mm}$ and $5{ }^{\circ} \mathrm{C}$ month $(50 \mathrm{~mm}$ and $100 \mathrm{~g}$ $\mathrm{C} \mathrm{m}^{-2}$ ) bin represents the maximum attainable vegetation cover for a given annual precipitation and $\mathrm{SWI}_{0}\left(A_{0}\right)$.

111 Climate bins containing less than 5 grid cells are not included in these plots. Coloured lines represent the fitted contour of $F_{\max }$, ranging from 0 to $80 \%$ with an interval of $10 \%$.

114 We developed a parsimonious model (see Methods) to investigate the observed changes of vegetation 115 cover in space and through time (Supplementary Fig. 7). This model is based on the principle that the 
116 carbon allocation to leaves results from the maximisation of net profit after all the costs of constructing and supporting leaves have been accounted for, subject to the constraint that water is 118 available to allow optimal functioning of the leaves. Model predicted $F_{\max }$ is consistent with satellite 119 observations (Fig. 3), with a correlation coefficient (r) between predicted and observed $F_{\max }$ of 0.76 120 and a root mean squared error (RMSE) of 0.12 . The model performed slightly better when vegetation 121 cover is higher, that is when $F_{\max }$ was $>0.5$. Correlations of the spatial patterns for individual years 122 ranged from 0.58 to 0.82 (Supplementary Fig. 8). Comparison of predicted $F_{\max }$ with field 123 measurements of aboveground biomass from 1689 plots across the Plateau (Supplementary Fig. 9) 124 shows the model also performs well at site level $(P<0.001)$ without any in-situ calibration. Moreover, 125 the model correctly predicted the observed divergent trends in dry versus wet areas (Fig. 4). The 126 model predicted an increase in $F_{\max }$ of $0.32 \pm 0.19 \% \mathrm{yr}^{-1}$ in the water limited areas, indistinguishable 127 from the satellite-observed trend of $0.31 \pm 0.14 \% \mathrm{yr}^{-1}$. In energy limited areas, the predicted $F_{\max }$ 128 decreased by $0.07 \pm 0.06 \% \mathrm{yr}^{-1}$, close to (though somewhat less than) the observed decline of $1290.12 \pm 0.08 \% \mathrm{yr}^{-1}$. The interannual variation in $F_{\max }$ is also well predicted by the model in both regions, 130 though slightly better in water limited regions $(r=0.75)$ than energy limited regions $(r=0.45)$.

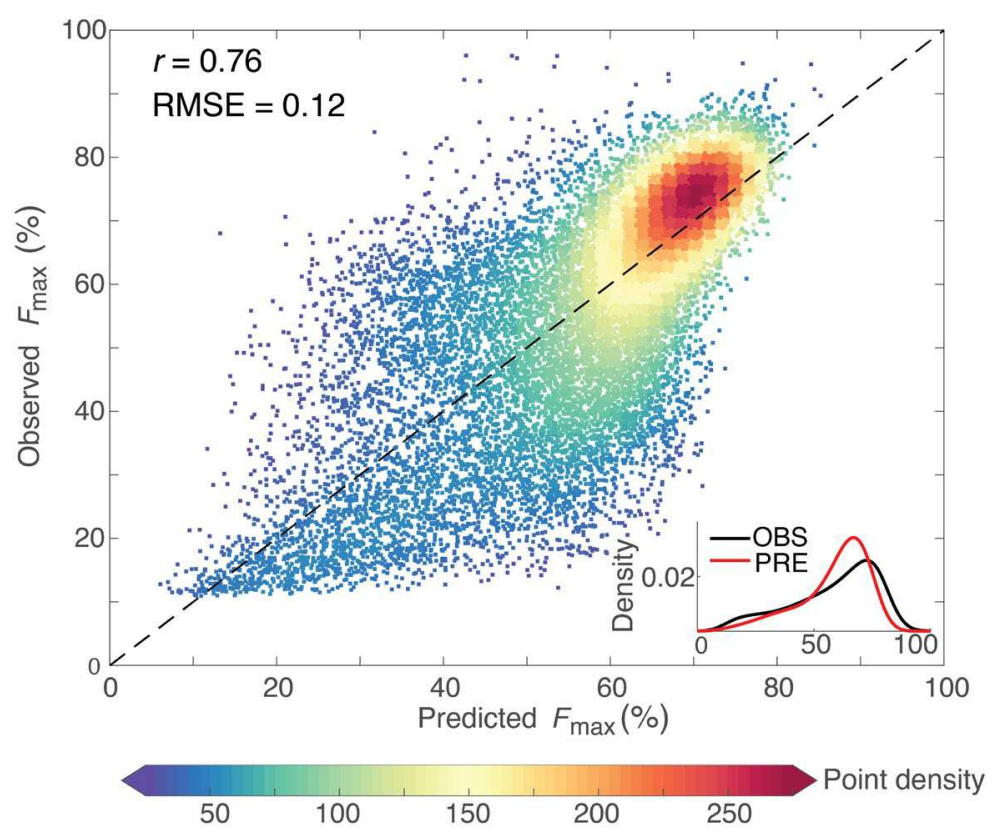

132 Fig. 3 | Comparison of estimated peak vegetation cover against observations. $F_{\max }$ data are collected in the 133 climate space of annual total precipitation and summer warmth index $\left(\mathrm{SWI}_{0}\right)$ over 1982-2016. The density of 134 points is represented by different colours. The black dashed line is the 1:1 line. The insert panel represents the 135 probability density of predicted and observed $F_{\max }$. 

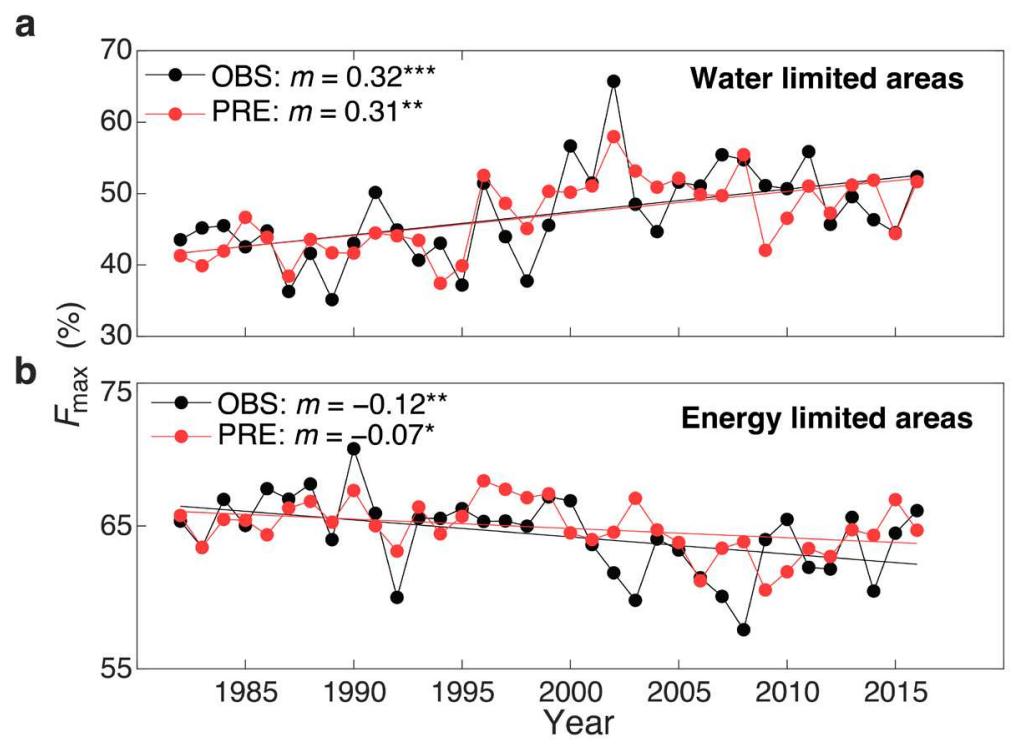

137 Fig. 4 | Trends in observed and predicted peak vegetation cover on the Tibetan Plateau. a, b, Annual time 138 series of observed GIMMS $F_{\max }$ (black line) and predicted $F_{\max }$ (Red line) in water limited areas (a) and energy 139 limited areas (b) over 1982-2016. $F_{\max }$ data are collected in the climate space of total precipitation and $\mathrm{SWI}_{0}$. The 140 solid lines show fitted linear regressions, with slope $m\left(\% \mathrm{yr}^{-1}\right)$ and $P$ values indicated $(* P<0.05 ; * * P<0.01$; $141 * * * P<0.001)$.

143 Factorial simulations, in which one environmental variable was allowed to change while the others 144 were held constant (see Methods), allowed us to diagnose the relative contribution of different 145 environmental factors to the observed trends in $F_{\max }$ (Fig. 6). Increasing precipitation was the major 146 driver of $F_{\max }$ trends in water limited areas $\left(0.30 \pm 0.12 \% \mathrm{yr}^{-1}\right)$ but was relatively unimportant in 147 energy limited areas $\left(0.010 \pm 0.004 \% \mathrm{yr}^{-1}\right)$. Increasing $\mathrm{CO}_{2}$ had a positive effect on vegetation cover 148 overall, but the effect was larger in water limited areas $\left(0.128 \pm 0.006 \% \mathrm{yr}^{-1}\right)$ than in energy limited 149 areas $\left(0.077 \pm 0.003 \% \mathrm{yr}^{-1}\right)$. Radiation had opposite effects in the two areas: increased radiation 150 reduced vegetation cover in water limited regions $\left(-0.100 \pm 0.035 \% \mathrm{yr}^{-1}\right)$ but encouraged vegetation 151 growth in energy limited regions $\left(0.104 \pm 0.040 \% \mathrm{yr}^{-1}\right)$. Increased VPD and warming had negative 152 effects in both areas, but when compared with other environmental factors, the impact of VPD and 153 warming was greater in energy limited areas $\left(-0.106 \pm 0.043 \% \mathrm{yr}^{-1},-0.132 \pm 0.031 \% \mathrm{yr}^{-1} \mathrm{respectively}\right)$ 154 than water limited areas $\left(-0.142 \pm 0.064 \% \mathrm{yr}^{-1},-0.078 \pm 0.026 \% \mathrm{yr}^{-1}\right.$ respectively). This difference in 155 response reflects the fact that increased atmospheric aridity and warming in energy limited areas necessitates increased below-ground allocation for nutrient and water uptake ${ }^{22,23}$ and is consistent 157 with an inferred increase in the unit cost of constructing and maintaining leaves $\left(z_{\text {cost }}\right)$ (Supplementary 158 Fig. 8). 


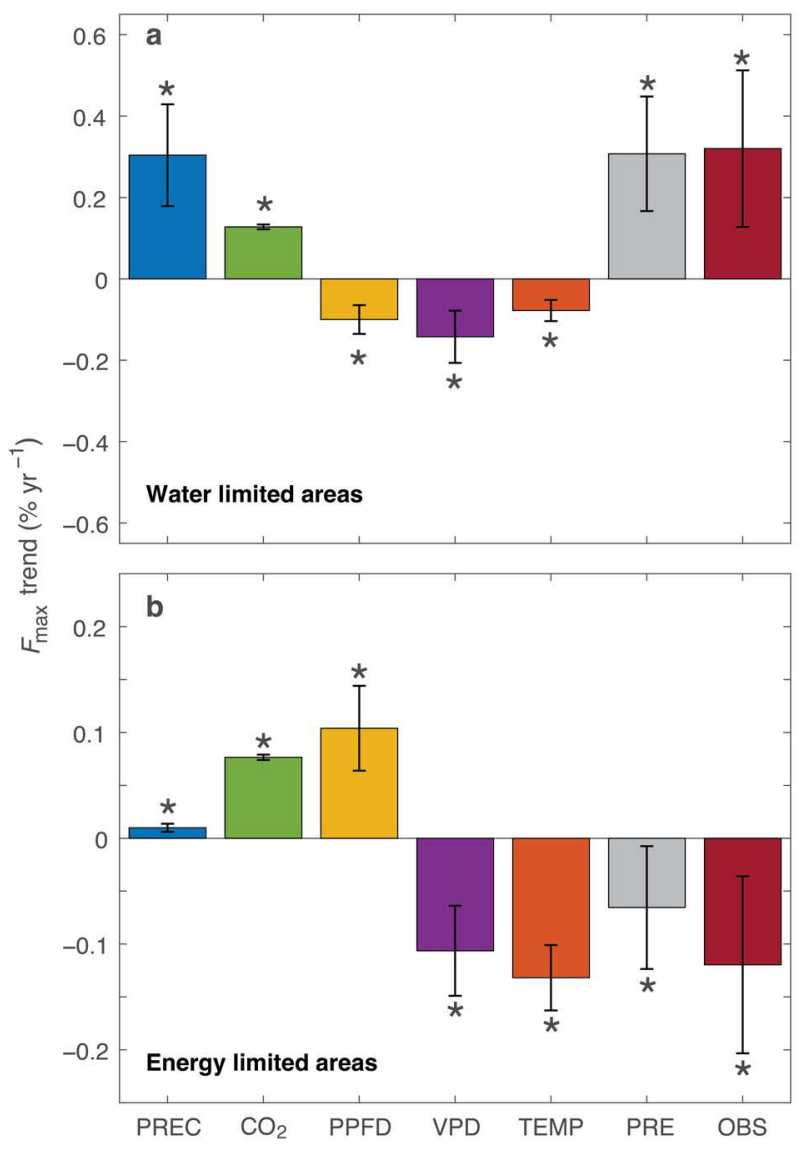

160 Fig. 5 | Attribution of trends in peak vegetation cover to various factors. a, $\mathbf{b}$, Trends in $F_{\max }$ derived from

161 observation (OBS) and modelled trends driven by precipitation (PREC), rising $\mathrm{CO}_{2}\left(\mathrm{CO}_{2}\right)$, photosynthetic photon 162 flux density (PPFD), vapour pressure deficit (VPD), temperature (TEMP) and all environmental factors (PRE) 163 using the Mann-Kendall test in water limited areas (a) and in energy limited areas (b). Error bars show the 95\% 164 confidence intervals of the regression. Statistically significant trends $(P<0.05)$ are marked with one asterisk.

166 Our analyses show that the relationship between vegetation cover and climate has weakened over the 167 past three decades (Fig. 6). Model predictions indicate that the sensitivity of vegetation cover to 168 precipitation decreased by $13.6 \pm 3.9 \%$ over the period between 1982 and 2016, while the sensitivity 169 to temperature decreased by $36.9 \pm 15.6 \%$. These declines in sensitivity are also seen in the satellite 170 observations. The interannual variation in observed sensitivity is also captured by the model, though 171 the performance of the model in predicting temperature sensitivity $(r=0.89)$ is slightly better than 172 predicting precipitation sensitivity $(r=0.64)$. Factorial simulations show that nearly half $(49.9 \pm 14.5 \%)$ 173 of the decrease in temperature sensitivity results from increased temperature (Supplementary Fig. 174 11b); the effect of increased temperature offsets the positive impacts of increased precipitation 175 (7.6 $\pm 6.9 \%)$, elevated $\mathrm{CO}_{2}(3.6 \pm 0.7 \%)$ and increased PPFD (21.6 $\left.\pm 10.0 \%\right)$ on vegetation growth. 176 These factorial simulations also show that recent increases in $\mathrm{CO}_{2}$ have a positive influence on the 
sensitivity of vegetation growth to precipitation (Supplementary Fig. 11a). This somewhat counterintuitive result reflects the fact that although water-use efficiency increases with elevated $\mathrm{CO}_{2}{ }^{24,25}$, the $\mathrm{CO}_{2}$ induced enhancement of growth places high demands on water availability. The positive effect of $\mathrm{CO}_{2}$ on the sensitivity of vegetation growth to increasing precipitation is offset by the negative influence of other variables. Specifically, the decreased sensitivity to precipitation is influenced both by changes in VPD and by changes in precipitation itself $\mathrm{f}^{26,27}$, which contribute $7.8 \pm 2.2 \%$ and $6.9 \pm 2.9 \%$ respectively to the decline in sensitivity. In water limited environments, plants respond to increases in VPD through stomatal closure ${ }^{28,29}$ and there is thus less transpiration and lower overall water demand. Under these conditions, increased precipitation does not translate into increased $F_{\max }$ because the water demand is already satisfied. The situation is different in energy limited regions, where increased VPD inhibits photosynthesis and therefore directly reduces growth and the need for water. The declining sensitivity to precipitation reflects the fact that as precipitation increases there is an overall shift from water limitation to energy limitation across the Tibetan Plateau, with water limited areas shrinking and energy limited areas expanding significantly (Supplementary Fig. 12). These changes mean there is a reduction in the water constraint on vegetation growth, such that vegetation growth becomes less sensitive to further increases in precipitation.

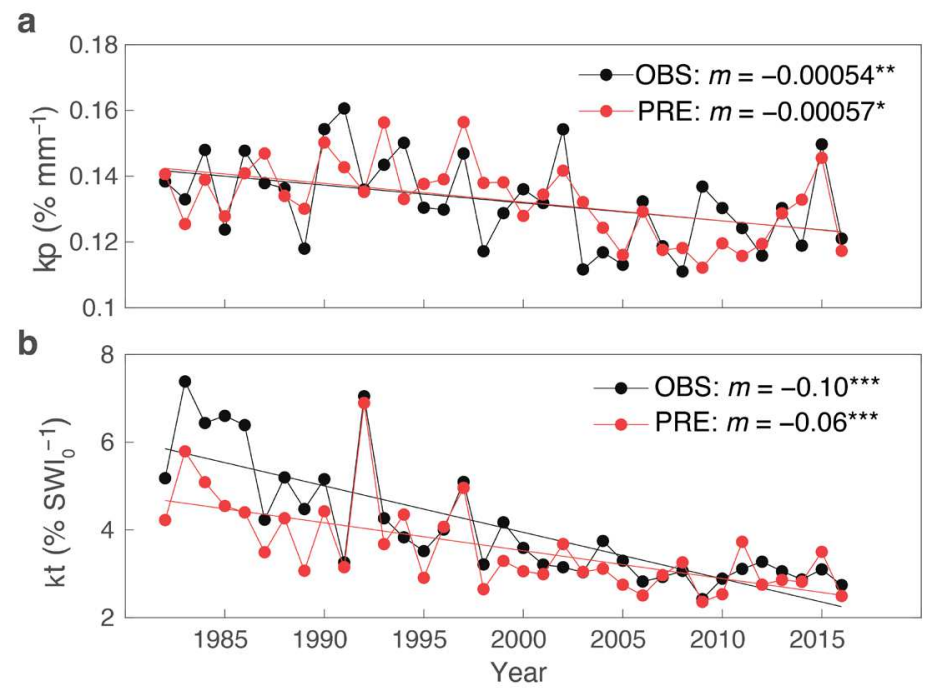

194 Fig. 6 | Weakened relationship between vegetation cover and climate. a, Annual time series of observed (black line) and predicted (red line) sensitivity of vegetation cover to precipitation $(\mathrm{kp})$ on the Tibetan Plateau over 1982-2016. b, Annual time series of observed (black line) and predicted (Red line) sensitivity of vegetation cover to temperature $(\mathrm{kt})$ on the Tibetan Plateau over 1982-2016. Both the observed and predicted sensitivity of peak vegetation cover to climate are obtained from log-sum-exp regression in the climate space of precipitation and $\mathrm{SWI}_{0}$. The solid lines show fitted linear regressions, with slope $m\left(\mathrm{a}, \% \mathrm{~mm}^{-1} \mathrm{yr}^{-1} ; \mathrm{b}, \% \mathrm{SWI}_{0}^{-1} \mathrm{yr}^{-1}\right)$ and $P$ values indicated $(* P<0.05 ; * * P<0.01 ; * * * P<0.001)$. 


\section{Discussion}

202 We have shown that a parsimonious modelling framework based on a theory of optimal plant function accounts for changes in vegetation cover both at individual sites and regionally. Annual peak vegetation cover has been used to track environmental constraints on terrestrial ecosystem productivity in previous studies ${ }^{6-8,10,21}$. However, the divergent responses of maximum seasonal vegetation cover to recent observed climate changes in water limited and energy limited areas of the Tibetan Plateau has not been noted before. The long-term increase in growing season PPFD had opposite effects on water use and energy uptake. In energy limited areas, the lengthening of the growing season ${ }^{19,30}$, and the consequent increase in cumulative radiation, stimulated photosynthesis ${ }^{31}$ (Supplementary Fig. 1c and d) and had a positive impact on vegetation cover. However, in water 211 limited (arid or semi-arid) regions, increased PPFD increased potential productivity $\left(A_{0}\right)$, resulting in 212 increased water demand per unit leaf area and, since water supply is limited, this imposed a constraint 213 on vegetation growth (Supplementary Fig. 11a). Increases in precipitation have partly offset the negative impact of increased radiation and warming in water limited areas ${ }^{32}$, but only had a minor (albeit positive) effect on vegetation cover in energy limited areas (Fig. 5b).

Increasing $\mathrm{CO}_{2}$ concentrations have had a positive influence on peak vegetation cover in both energy and water limited areas (Fig. 5 and Supplementary Fig. 11). The same phenomenon has been observed in field experiments ${ }^{33,34}$. In energy limited areas, increased $\mathrm{CO}_{2}$ concentration is expected to increase vegetation cover due to enhanced photosynthesis ${ }^{2,9,35}$. Increased water use efficiency with increasing atmospheric $\mathrm{CO}_{2}$ concentration ${ }^{7,8,25}$ reduces the water constraint in water limited areas. In contrast, the recent increasing trend in VPD has had a negative impact on peak vegetation growth in both energy and water limited areas, a phenomenon noted in global analyses ${ }^{29}$. Increased VPD triggers stomatal closure, a mechanism for reducing water loss, leading to a decline in photosynthesis ${ }^{29,36}$.

Our analyses indicate that warming leads to changes in allocation, consistent with other observations and experimental evidence ${ }^{22,23}$. Liu et al. $^{23}$, for example, have shown that warming leads to a shift towards deeper rooting and more below-ground carbon allocation in alpine grasslands, allowing plants to acquire more water and nutrients. The observed decline in vegetation sensitivity to warming over the past three decades, noted in other studies ${ }^{10,13,14}$, may similarly reflect increased below-ground carbon allocation. 
233 Our study confirms that the sensitivity of vegetation growth to increasing temperature has weakened 234 in recent decades, as shown in other studies ${ }^{10,13,14}$. The magnitude of this decrease $(36.9 \pm 15.6 \%)$ on 235 the Tibetan Plateau between 1982 and 2016 is similar to the value of $32.8 \%$ obtained from the 236 analyses of the northern extratropics for the period between 1982 and $2012^{10}$. In contrast to the 237 findings of Keenan and Riley ${ }^{10}$ for the northern extratropics, this declining sensitivity does not 238 translate into a reduction of the area that is energy limited on the Tibetan Plateau which expands by $23911.8 \%$ over the period 1982 to 2016 . This appears to be the result of the interplay between temperature 240 and changes in other climate factors. The substantial increase in precipitation over the Plateau results 241 in a decline in the area that is water limited but is insufficient to overcome the additional costs of constructing and maintaining leaves in energy-limited regions resulting from the increased radiation and atmospheric dryness. There have been several studies that have shown that increasing precipitation has led to increased vegetation growth in dry regions ${ }^{26,27}$, and thus a reduction in the area of water limitation as in the Tibetan Plateau. However, these studies do not explicitly examine changes in the overall sensitivity to increasing precipitation, which we have shown has also weakened in recent decades albeit at a lower rate than the sensitivity to temperature. Understanding how this change in sensitivity to precipitation will affect the response to temperature will be important for understanding future changes in vegetation growth.

Process-based global vegetation models have been used to explore the causes of recent changes in vegetation cover ${ }^{3,6}$. However, the global climate data sets used to drive these simulations represent the climate of the Tibetan Plateau poorly (see Supplementary Figs 14 and 15) and this precludes any direct comparison of our results with existing process-based simulations. Nevertheless, ecoevolutionary optimality (EEO) $)^{37,38}$ approaches have been shown to provide as good a representation of ecosystem processes as more complex global vegetation models ${ }^{39,40}$, and our analyses suggest that these approaches provide a useful alternative way of exploring the causes of recent vegetation changes.

\section{Conclusion}

262 Despite having experienced similar climate trends over the last three decades, drier regions of the 263 Tibetan Plateau have shown enhanced vegetation cover (greening) while wetter regions have shown 264 decreased peak seasonal vegetation cover (browning). These divergent responses can be explained 265 using a model that invokes limitation of vegetation growth by energy or water. While recent increases in $\mathrm{CO}_{2}$ have tended to increase vegetation cover in both energy and water limited regions, changes in 
temperature and atmospheric dryness (VPD) have impacted these regions differently. Warming has brought additional allocation costs, weakening the sensitivity of vegetation to temperature increases, particularly in energy limited regions. This parsimonious modelling framework based on ecoevolutionary theory ${ }^{37,38}$ has thus succeeded in predicting maximum vegetation cover and its temporal trends, and the unexpected spatial divergence of these trends across the Tibetan Plateau. Our analysis demonstrates the potential of parsimonious EEO-based modelling to reveal the mechanisms underlying recent trends in vegetation cover and its sensitivity to climate change.

\section{Methods}

\section{Satellite data:}

We used GIMMS third-generation fraction of absorbed photosynthetically active radiation fAPAR (fAPAR3g) dataset ${ }^{41}$ as an index of vegetation cover. fAPAR is a main driver of vegetation productivity $^{42,43}$ and has been widely employed to track the environmental limitations on vegetation $^{10,44}$. The extended version of this data set covers the interval of 1982-2016 (http://sites.bu.edu/cliveg/datacodes/), with a spatial resolution of $1 / 12^{\circ}$ and a temporal resolution of 2 weeks and it was resampled to $0.1^{\circ}$ using bilinear interpolation to match the spatial resolution of climate data.

We determined the annual maximum fAPAR data as the peak greenness, a proxy for the capacity of ecosystem primary production ${ }^{6}$, at each $0.1^{\circ}$ grid cell from the biweekly composites. The maximum fAPAR $\left(F_{\max }\right)$ at each geographic grid was then binned in climate space determined by the corresponding annual total precipitation and summer warmth index $\left(\mathrm{SWI}_{0}\right.$, the sum of the monthly mean temperatures above $0{ }^{\circ} \mathrm{C}$ ). The bin width was arbitrarily set to $50 \mathrm{~mm}$ for precipitation and 5 ${ }^{\circ} \mathrm{C}$ month for $\mathrm{SWI}_{0}$. In each climate bin, by selecting $F_{\max }$ in the upper $90-95$ th percentile, we identified the grid cells with maximum fAPAR attainable for a given amount of precipitation and temperature and the corresponding environmental variables for these grid cells. This binning procedure is designed to disentangle the respective effects of water and heat supply in limiting peak growth of vegetation and minimise the impact of non-climatic influences on greenness on the analyses Similar analyses were used in the climate space determined by annual total precipitation and potential gross primary production $\left(A_{0}\right)$ with the bin width of $50 \mathrm{~mm}$ for precipitation and $100 \mathrm{~g} \mathrm{C} \mathrm{m}^{-2} \mathrm{yr}^{-1}$ for $A_{0}$. Climate bins with less than 5 grid cells were not included in this analysis. Vegetation dynamics on the Tibetan Plateau were examined with $F_{\max }$ data in both geographic and climate space using ordinary least squares linear regression. 


\section{Climatic variables}

302 We obtained daily climate data for the period 1982-2016 from the China Meteorological Forcing 303 Dataset (CMFD) at a 0.5 degree spatial resolution ${ }^{45}$ (http://data.tpdc.ac.cn/en/data/8028b944-daaa304 4511-8769-965612652c49/). The meteorological elements of CMFD used in this study were specific 305 humidity $(q)$, air pressure $(p)$, air temperature $(T)$, precipitation (PREC), and downward shortwave 306 radiation $(\mathrm{Srad})$.

Using the CMFD data, we calculated vapour pressure deficit (VPD, Pa) as the difference between saturated vapour pressure $\left(e_{\mathrm{s}}, \mathrm{Pa}\right)$ and actual vapour pressure $\left(e_{\mathrm{a}}, \mathrm{Pa}\right)$ :

$$
\mathrm{VPD}=e_{S}-e_{\mathrm{a}}=611.0 \cdot \mathrm{e}^{\left(\frac{17.27 T}{T+237.3}\right)}-\frac{p q}{0.378 q+0.622}
$$

310 Here, $T$ is air temperature $\left({ }^{\circ} \mathrm{C}\right) . p$ is air pressure $(\mathrm{Pa})$ and $q$ is specific humidity $(\mathrm{kg} / \mathrm{kg})$.

312 Following Meek et al. ${ }^{46}$, we derived photosynthetic photon flux density (PPFD) from solar radiation 313 (Srad):

$$
\text { PPFD }=60 \cdot 60 \cdot 24 \cdot 2.04 \cdot 10^{-6} \cdot \operatorname{Srad}
$$

314 where, PPFD is the daily photosynthetic photo flux density ( $\mathrm{mol} \mathrm{m}^{-2} \mathrm{~d}^{-1}$ ); Srad is daily mean 315 downward shortwave radiation $\left(\mathrm{W} \mathrm{m}^{-2}\right)$.

317 Air temperature and VPD were averaged over the growing season, defined as the period of the year 318 when air temperature is continuously above $0{ }^{\circ} \mathrm{C}$. PPFD was also accumulated over the growing 319 season. Precipitation was accumulated over the whole year. The annual time series of atmospheric $320 \mathrm{CO}_{2}$ concentration between 1982 and 2016 was obtained from the National Oceanic and Atmospheric Administration Earth System Research Laboratory (NOAA:

$322 \mathrm{https} / /$ www.esrl.noaa.gov/gmd/ccgg/trends/). We used ordinary least squares regression to calculate 323 the trends of long-term annual total precipitation (PREC), growing season mean vapour pressure 324 deficit (VPD), summer warmth index $\left(\mathrm{SWI}_{0}\right)$, growing season accumulated photosynthesis photo flux density (PPFD) and atmospheric $\mathrm{CO}_{2}$ concentration $\left(\mathrm{CO}_{2}\right)$.

Besides CMFD dataset, we also obtained daily climate data from Climatic Research Unit-National Centers for Environmental Prediction (CRU-NCEP) dataset, consisting of air temperature, 329 precipitation, solar radiation, specific humidity, and air pressure, with the spatial resolution of 0.5 330 degree $^{47}$. This dataset is the climate forcing of Trends in Net Land Carbon Exchange (TRENDY) 
331 Inter-model Comparison Project. We evaluated the performance of this global climate driving data 332 set on the Tibetan Plateau by comparing the spatial distributions and temporal trends of climate 333 variables derived from CRU-NCEP and CMFD datasets.

\section{log-sum-exp regression analysis}

336 We applied log-sum-exp regression ${ }^{48}$, which fits a continuous approximation to the minimum 337 function, to explore the spatial dependence of vegetation cover on precipitation and $\mathrm{SWI}_{0}$. A mixed 338 effect model in the 'nlmefit' function of MATLAB was used to perform this non-linear regression 339 with the 'year' as the random effect using the formula:

$$
F_{\max }=-\frac{1}{K} \ln \left(\mathrm{e}^{-K \mathrm{kp} P R E C}+\mathrm{e}^{-K \mathrm{ktSWI}_{0}}+\mathrm{e}^{-K f_{\max }}\right)
$$

340 where maximum fAPAR $\left(F_{\max }\right)$ is the response variable, precipitation (PREC, mm) and summer 341 warmth index $\left(\mathrm{SWI}_{0},{ }^{\circ} \mathrm{C}\right.$ month) are the predictor variables. $K, \mathrm{kp}$, $\mathrm{kt}$ and $f_{\max }$ are the parameters.

343 The greater the value $K$, the closer this function is to the minimum function. Here, as Peng et al. ${ }^{48}$ 344 recommended, $K$ was set as a constant $10 . \mathrm{kp}$ and $\mathrm{kt}$ fitted by observations, are expressed as the 345 change in $F_{\max }$ with for a unit increase of precipitation and temperature, i.e., the sensitivity of $F_{\max }$ to 346 the precipitation and temperature in units of $\% \mathrm{~mm}^{-1}$ and $\%{ }^{\circ} \mathrm{C} \mathrm{month}^{-1}$ respectively. $f_{\max }$, set as a constant (0.95), represents the maximum possible fraction of PAR that can be absorbed by the canopy $^{49,50}$.

\section{Modelling of maximum vegetation cover}

351 By coupling the eco-evolutionary optimality and hydro-climatological rate limitation framework with

352 a universal primary production model ( $\mathrm{P}$ model $)^{38,51-53}$, we propose a theory to investigate patterns of 353 vegetation cover in space and time. The basic hypothesis is that peak vegetation cover is limited either 354 by energy supply (in which case, allocation to leaves maximises net energy profit) and water supply.

\section{- Prediction of potential gross primary production:}

The P model is a universal and extensively tested light use efficiency (LUE) model ${ }^{31,54,55}$ to predict gross primary production (GPP) by plants. It is based on the Farquhar-von Caemmerer-Berry (FvCB) model for biochemical processes ${ }^{56}$ combined with eco-evolutionary optimality hypotheses ( the leastcost and coordination hypotheses) to represent the adaptation of stomatal behaviour and photosynthetic capacities to environmental conditions ${ }^{52,57}$. The least-cost hypothesis states that plants minimize the summed costs of maintaining carboxylation and transpiration capacity by regulating 
363 their leaf-internal $\mathrm{CO}_{2}$ concentration ${ }^{57}$. The coordination hypothesis states that the carboxylation364 limited rate $\left(A_{\mathrm{c}}\right)$ and electron transport-limited rate $\left(A_{\mathrm{J}}\right)$ of photosynthesis, the lesser of which 365 determines the instantaneous photosynthetic rate, tend to equality ${ }^{55}$. Comparisons between predicted 366 GPP and eddy covariance data show the P model performs as well as more complex models ${ }^{40,53}$.

368 Based on the P model, GPP $(A)$ can be expressed as a product of fAPAR and potential gross primary 369 production $\left(A_{0}\right)$ :

$$
A=\operatorname{fAPAR} A_{0}
$$

370 where $A_{0}$ is the product of light use efficiency (LUE) and incident photosynthetically active radiation 371 (PAR):

$$
A_{0}=\text { PAR LUE }
$$

372 In equation (5):

$$
\begin{gathered}
\text { LUE }=\varphi_{0} m \sqrt{1-\left(\frac{c^{*}}{m}\right)^{\frac{2}{3}}} \\
m=\frac{\left(c_{\mathrm{i}}-\Gamma^{*}\right)}{\left(c_{\mathrm{i}}-2 \Gamma^{*}\right)} \\
\chi=\frac{c_{\mathrm{i}}}{c_{\mathrm{a}}}=\frac{\Gamma^{*}}{c_{\mathrm{a}}}+\left(1-\frac{\Gamma^{*}}{c_{\mathrm{a}}}\right) \frac{\xi}{(\xi+\sqrt{\mathrm{VPD}})} \\
\xi=\sqrt{\frac{\beta\left(K+\Gamma^{*}\right)}{1.6 \eta^{*}}}
\end{gathered}
$$

373 where PAR is photosynthetically active radiation ( $\left.\mathrm{mol} \mathrm{m}^{-2} \mathrm{~d}^{-1}\right)$, calculated from Srad by eq. (2); $\varphi_{0}$ 374 is the intrinsic quantum yield of photosynthesis ( $\mathrm{mol} \mathrm{CO} \mathrm{Col}^{-1}$ photon). $m$ reflects the impact of 375 leaf-internal $\mathrm{CO}_{2}$ on carbon assimilation, determined by the leaf-internal $\mathrm{CO}_{2}$ partial pressure $\left(c_{\mathrm{i}}, \mathrm{Pa}\right)$ 376 and the $\mathrm{CO}_{2}$ partial pressure compensation point $\left(\Gamma^{*}, \mathrm{~Pa}\right) ; \chi$ is the ratio of the leaf-internal to ambient $377 \mathrm{CO}_{2}$ partial pressure $\left(c_{\mathrm{a}}, \mathrm{Pa}\right)$; VPD is vapour pressure deficit $(\mathrm{Pa}) ; \eta^{*}$ the viscosity of water relative to its value at $25^{\circ} \mathrm{C}$ (dimensionless); $K$ is the effective Michaelis-Menten coefficient of Rubisco (Pa) at a given temperature and atmospheric pressure. Two dimensionless constants $\left(c^{*}=0.41\right.$ and $\left.\beta=146\right)$ are globally estimated from independent data. The $\mathrm{P}$ model code is available at https://github.com/stineb/rpmodel.

- The eco-evolutionary-optimality-based energy limitation:

385 We propose that plants maximize net energy profit after the costs of constructing and supporting leaves are accounted for. fAPAR is estimated from leaf area index (LAI) by Beer's law ${ }^{58}$ : 


$$
\mathrm{fAPAR}=1-\mathrm{e}^{-k \mathrm{LAI}}
$$

387 where LAI $\left(\mathrm{m}^{2} \mathrm{~m}^{-2}\right)$ is projected leaf area per unit ground area and $k=0.5$ is the extinction coefficient 388 for photosynthetically active radiation.

390 Net energy profit $\left(P_{\mathrm{n}}\right)$ is assumed to be equal to the difference between the energy gain through 391 assimilation (GPP) and the cost of constructing and maintaining leaves:

$$
P_{\mathrm{n}}=\mathrm{GPP}-z_{\text {cost }} \text { LAI }
$$

392 where, $z_{\text {cost }}\left(\mathrm{mol} \mathrm{C} \mathrm{m} \mathrm{yr}^{-1}\right)$ depends on climate. It should be larger when the photosynthetic 393 characteristics of vegetation are affected by warming or increased aridity at relatively higher 394 temperature, lower soil moisture, and/or higher vapour pressure deficit since more carbon needs to be allocated to root construction ${ }^{23,59}$. Note that although both GPP and LAI have a large spatial variation, $z_{\text {cost }}$ expresses the unit carbon cost requirements for the leaf, which varies much less across the Tibetan Plateau with grassland as the dominant vegetation coverage. Therefore, $z_{\text {cost }}$ was set a constant across the Tibetan Plateau each year.

Substituting equation (11) to equation (10), net profit can be expressed as:

$$
P_{\mathrm{n}}=A_{0}\left(1-\mathrm{e}^{-k \mathrm{LAI}}\right)-z_{\text {cost }} \mathrm{LAI}
$$

401 When the first derivative of equation (12) is equal to zero, the net energy profit is maximized since 402 the second derivative of equation (12) is always negative:

$$
\frac{\partial P_{\mathrm{n}}}{\partial \mathrm{LAI}}=k A_{0} \mathrm{e}^{-k \mathrm{LAI}}-z_{\mathrm{cost}}=0
$$

403 The solution of equation (13) can then be written as:

$$
\mathrm{LAI}=\frac{1}{k} \ln \left(k \frac{A_{0}}{z_{\text {cost }}}\right)
$$

404 Substituting equation (9) in equation (13) yields energy limited fAPAR (fAPAR energy): ):

$$
\text { fAPAR }_{\text {energy }}=1-\frac{z_{\text {cost }}}{k A_{0}}
$$

405 The formula shows that in energy limited conditions, peak vegetation cover should only be controlled 406 by energy supply. The greater the $A_{0}$, the larger the fAPAR.

\section{- The mass-balance-based water limitation:}

409 The mass-balance-based water limitation requires that transpiration (accompanied by carbon 410 assimilation) should be matched by the water supply from precipitation ${ }^{60,61}$. We assume that 411 vegetation makes use of a certain fraction $\left(f_{0}\right)$ of precipitation to maintain its capacity for 412 photosynthesis. 


$$
T=f_{0} \text { PREC }
$$

413 where $T$ is the total transpiration in the growing season $\left(\mathrm{mm} \mathrm{yr}^{-1}\right)$. PREC is annual total precipitation

$414\left(\mathrm{~mm} \mathrm{yr}^{-1}\right) \cdot f_{0}$ is the ratio of precipitation to transpiration (dimensionless), which depends on the 415 partitioning of evapotranspiration (ET) and precipitation. To simply the model, $f_{0}$ is set as a constant 416 throughout the Tibetan Plateau.

417

418 Water demand of vegetation can be estimated by Fick's Law ${ }^{62}$ :

$$
T=1.6 G_{\mathrm{s}} \mathrm{VPD}
$$

419 where $G_{\mathrm{s}}$ is canopy conductance to $\mathrm{CO}_{2}$.

421 Carbon assimilation, accompanied by transpiration, can be expressed as a function of canopy 422 conductance $\left(G_{\mathrm{s}}\right)$, ambient $\mathrm{CO}_{2}$ concentration $\left(c_{\mathrm{a}}\right)$ and the ratio of leaf-internal $\mathrm{CO}_{2}\left(c_{\mathrm{i}}\right)$ to $c_{\mathrm{a}}(\chi)$ using 423 Fick's law as well:

$$
\mathrm{GPP}=G_{\mathrm{s}} c_{\mathrm{a}}(1-\chi)
$$

Then, substituting equations (4) and (18) into (17), $T$ can be calculated as:

$$
T=\frac{1.6 \mathrm{fAPAR} A_{0} \mathrm{VPD}}{c_{\mathrm{a}}(1-\chi)}
$$

426 Derived from equation (16) and (19), based on the water mass-balance, water limited vegetation cover 427 (fAPAR water $)$ can be calculated as:

$$
\text { fAPAR }_{\text {water }}=\frac{c_{\mathrm{a}}(1-\chi) f_{0} \text { PREC }}{1.6 \operatorname{VPD} A_{0}}
$$

\section{- Parameter estimation:}

430 This framework posits that peak vegetation cover should be determined by the lesser of the water and 431 energy limited vegetation cover $^{61}$. $F_{\max }$ can then be expressed as:

$$
F_{\text {max }}=\min \left[1-\frac{z_{\text {cost }}}{k A_{0}}, \frac{c_{\mathrm{a}}(1-\chi) f_{0} \text { PREC }}{1.6 \operatorname{VPD} A_{0}}, f_{\max }\right]
$$

432 Here, $f_{\max }$ is set as a constant $(0.95)^{49,50}$. It represents the maximum achievable fAPAR and is 433 independent of other parameters. $f_{0}$ (the ratio of total precipitation to water supply) and $z_{\text {cost }}$ (unit 434 carbon cost of construction and maintenance of leaves) are fitted by the observed fAPAR and climate 435 data using log-sum-exp regression: 


$$
F_{\max }=-\frac{1}{K} \ln \left[\mathrm{e}^{-K\left(1-\frac{z_{\text {cost }}}{k A_{0}}\right)}+\mathrm{e}^{-K \frac{c_{\mathrm{a}}(1-\chi) f_{0} \text { PREC }}{1.6 \mathrm{VPD} A_{0}}}+\mathrm{e}^{-K f_{\max }}\right]
$$

\section{Above-ground biomass data}

438 We used site-based measurements of aboveground biomass as an additional validation of the model 439 performance. Aboveground biomass measurements from 1689 sites on the Tibetan Plateau 440 complied by Xia et al. ${ }^{63}$ were obtained from https://iopscience.iop.org/article/10.1088/1748441 9326/aa9997/data. The measurements were all taken in July and early August, at the peak of 442 vegetation growth on the Plateau and are thus comparable to $F_{\max }$. The site data were projected in 443 the climate space of $\mathrm{SWI}_{0}$ and precipitation, with bin widths arbitrarily set to $5{ }^{\circ} \mathrm{C}$ month for $\mathrm{SWI}_{0}$ 444 and $50 \mathrm{~mm}$ for precipitation. We then selected the biomass data at the upper 85-95th percentile and 445 the corresponding fAPAR in each climate-space bin to identify grid cells with peak vegetation 446 cover attainable for a given amount of precipitation and temperature.

\section{Diagnosing the contribution of environmental factors}

449 We applied our model to diagnose the driving forces of greening and browning of the Tibetan Plateau. 450 Six simulations with different inputs were used to assess the ability of the model to predict response 451 patterns of vegetation cover to climate change and environmental factors. In the first simulation 452 (SIM), all input variables varied over time. In the other five experiments (PREC, $\mathrm{CO}_{2}, \mathrm{PPFD}, \mathrm{VPD}$, 453 TEMP), the named input variable was held constant at its median value over the 35 years and the 454 other variables were allowed to vary realistically. The difference between the SIM and each of the 455 individual variable simulations provides a measure of the effect of single drivers. Similar analyses 456 were used to diagnose the contribution of individual environmental factors to the trends in 457 precipitation and temperature sensitivity.

\section{Data availability}

460 The GIMMS3g fAPAR data are available on NASA NEX (see instructions at 461 http://sites.bu.edu/cliveg/datacodes/). The CMFD climate datasets underlying analysis are publicly 462 available at Third Pole Environment Data Centre (http://data.tpdc.ac.cn/en/data/8028b944-daaa463 4511-8769-965612652c49/). The CRU-NCEP climate dataset can be obtained from 464 https://rda.ucar.edu/datasets/ds314.3/. Aboveground biomass measurements from 1689 sites on the 465 Tibetan Plateau complied by Xia et al. $^{63}$ can be downloaded at 466 https://iopscience.iop.org/article/10.1088/1748-9326/aa9997/data. 


\section{Acknowledgements}

This study was funded by the National Natural Science Foundation of China (32022052, 31971495, 91837312). I.C.P. and S.P.H. are supported by the High-End Foreign Expert program of the China State Administration of Foreign Expert Affairs at Tsinghua University (G20190001075, G20200001064). S.P.H. also acknowledges the support from the ERC-funded project GC2.0 (Global Change 2.0: Unlocking the past for a clearer future, No. 694481). I.C.P. also acknowledges support from the European Research Council under the European Union's Horizon 2020 research and innovation programme (Grant Agreement No: 787203 REALM). This research is a contribution to the Land Ecosystem Models based On New Theory, obseRvations and ExperimEnts (LEMONTREE) project funded through the generosity of Eric and Wendy Schmidt by recommendation of the Schmidt Futures program and to the Imperial College initiative on Grand Challenges in Ecosystems and the Environment. We thank members of the LEMONTREE LAI working group for helpful feedback on this study.

\section{Author contributions}

H.W., I.C.P. and S.P.H. designed the study. Z.Z. performed the analysis. S.Q. and S.T. contributed to the idea development. I.C.P and S.P.H contributed to the interpretation of the results. H.W. and Z.Z. wrote the first draft. All authors participated in the revision of the manuscript.

\section{Competing interests}

The authors declare no competing interests.

\section{References:}

1. Chen, C. et al. China and India lead in greening of the world through land-use management. Nat. Sustain. 2, 122-129 (2019).

2. Piao, S. et al. Characteristics, drivers and feedbacks of global greening. Nat. Rev. Earth Environ. 1, 14-27 (2019).

3. Zhu, Z. et al. Greening of the Earth and its drivers. Nat. Clim. Change 6, 791-795 (2016).

4. Bonan, G. B., Doney S. C. Climate, ecosystems, and planetary futures: The challenge to predict life in Earth system models. Science 359, eaam8328 (2018).

5. Myers-Smith, I. H. et al. Complexity revealed in the greening of the Arctic. Nat. Clim. Change 10, 106-117 (2020).

6. Huang, K. et al. Enhanced peak growth of global vegetation and its key mechanisms. Nat. Ecol. Evol. 2, 1897-1905 (2018).

7. Ukkola, A. M. et al. Reduced streamflow in water-stressed climates consistent with $\mathrm{CO}_{2}$ effects on vegetation. Nat. Clim. Change 6, 75-78 (2015).

8. Donohue, R. J., Roderick M. L., McVicar T. R., Farquhar G. D. Impact of $\mathrm{CO}_{2}$ fertilization on maximum foliage cover across the globe's warm, arid environments. Geophys. Res. Lett. 40, 3031-3035 (2013). 
9. Keenan, T. F. et al. A constraint on historic growth in global photosynthesis due to increasing $\mathrm{CO}_{2}$. Nature 600, 253-258 (2021).

10. Keenan, T. F., Riley W. J. Greening of the land surface in the world's cold regions consistent with recent warming. Nat. Clim. Change 8, 825-828 (2018).

11. Huang, M. et al. Velocity of change in vegetation productivity over northern high latitudes. Nat. Ecol. Evol. 1, 1649-1654 (2017).

12. Berner, L. T. et al. Summer warming explains widespread but not uniform greening in the Arctic tundra biome. Nat. Commun. 11, 4621 (2020).

13. Piao, S. et al. Weakening temperature control on the interannual variations of spring carbon uptake across northern lands. Nat. Clim. Change 7, 359-363 (2017).

14. Piao, S. et al. Evidence for a weakening relationship between interannual temperature variability and northern vegetation activity. Nat. Commun. 5, 5018 (2014).

15. Yao, T. et al. Third Pole Environment (TPE). Environ. Dev. 3, 52-64 (2012).

16. Kuang, X., Jiao J. J. Review on climate change on the Tibetan Plateau during the last half century. J. Geophys. Res. Atmos. 121, 3979-4007 (2016).

17. Yang, K. et al. Recent climate changes over the Tibetan Plateau and their impacts on energy and water cycle: A review. Glob. Planet Change 112, 79-91 (2014).

18. Yao, T. et al. Recent Third Pole's rapid warming accompanies cryospheric melt and water cycle intensification and interactions between monsoon and environment: multidisciplinary approach with observation, modeling and analysis. Bull. Am. Meteorol. Soc. 100, 423-444 (2019).

19. Shen, M. G. et al. Plant phenological responses to climate change on the Tibetan Plateau: research status and challenges. Natl. Sci. Rev. 2, 454-467 (2015).

20. Wang, X. et al. Multisatellite Analyses of Spatiotemporal Variability in Photosynthetic Activity Over the Tibetan Plateau. J. Geophys. Res. Biogeosci. 124, 3778-3797 (2019).

21. Vicca, S. Global vegetation's $\mathrm{CO}_{2}$ uptake. Nat. Ecol. Evol. 2, 1840-1841 (2018).

22. Xu, X. et al. Climate warming promotes deterministic assembly of arbuscular mycorrhizal fungal communities. Glob. Chang. Biol. (2021).

23. Liu, H. et al. Shifting plant species composition in response to climate change stabilizes grassland primary production. Proc. Natl Acad. Sci. USA 115, 4051-4056 (2018).

24. Cheng, L. et al. Recent increases in terrestrial carbon uptake at little cost to the water cycle. Nat. Commun. 8, 110 (2017).

25. Keenan, T. F. et al. Increase in forest water-use efficiency as atmospheric carbon dioxide concentrations rise. Nature 499, 324-327 (2013).

26. Maurer, G. E. et al. Sensitivity of primary production to precipitation across the United States. Ecol. Lett. 23, 527-536 (2020).

27. Liu, D. et al. Increasing climatic sensitivity of global grassland vegetation biomass and species diversity correlates with water availability. New Phytol. 230, 1761-1771 (2021).

28. Ding, J. et al. Increasingly important role of atmospheric aridity on Tibetan Alpine grasslands. Geophys. Res. Lett. 45, 2852-2859 (2018).

29. Yuan, W. et al. Increased atmospheric vapor pressure deficit reduces global vegetation growth. Sci. Adv. 5, eaax1396 (2019).

30. Yang, Z. et al. Asymmetric responses of the end of growing season to daily maximum and minimum temperatures on the Tibetan Plateau. J. Geophys. Res. Atmos. 122, 13,278-213,287 (2017).

31. Ren, Y. et al. The south Asia monsoon break romotes grass growth on the Tibetan Plateau. $J$. Geophys. Res. Biogeosci. 126, e2020JG005951 (2021).

32. Zhao, J. et al. Increased precipitation offsets the negative effect of warming on plant biomass and ecosystem respiration in a Tibetan alpine steppe. Agric. For. Meteorol. 279 (2019). 
33. Ainsworth, E. A., Long S. P. What have we learned from 15 years of free-air $\mathrm{CO}_{2}$ enrichment (FACE)? A meta-analytic review of the responses of photosynthesis, canopy properties and plant production to rising $\mathrm{CO}_{2}$. New Phytol. 165, 351-371 (2005).

34. Zhu, J. et al. Synergistic effects of nitrogen and $\mathrm{CO}_{2}$ enrichment on alpine grassland biomass and community structure. New Phytol. 228, 1283-1294 (2020).

35. Poorter, $\mathrm{H}$. et al. A meta-analysis of responses of $\mathrm{C} 3$ plants to atmospheric $\mathrm{CO}_{2}$ : dose-response curves for 85 traits ranging from the molecular to the whole-plant level. New Phytol. (2021).

36. Smith, M. N. et al. Empirical evidence for resilience of tropical forest photosynthesis in a warmer world. Nat. Plants 6, 1225-1230 (2020).

37. Franklin, O. et al. Organizing principles for vegetation dynamics. Nat. Plants 6, 444-453 (2020).

38. Harrison, S. P. et al. Eco-evolutionary optimality as a means to improve vegetation and landsurface models. New Phytol. 231, 2125-2141 (2021).

39. De Kauwe, M. G. et al. A test of an optimal stomatal conductance scheme within the CABLE land surface model. Geosci. Model Dev. 8, 431-452 (2015).

40. Mengoli, G. et al. Ecosystem photosynthesis in land - surface models: a first - principles approach incorporating acclimation. J. Adv. Model. Earth Syst. (2021).

41. Zhu, Z. et al. Global data sets of vegetation leaf area index (LAI)3g and fraction of photosynthetically active radiation (FPAR) $3 \mathrm{~g}$ derived from global inventory modeling and mapping studies (GIMMS) normalized difference vegetation index (NDVI3g) for the period 1981 to 2011. Remote Sens. 5, 927-948 (2013).

42. Ryu, Y., Berry J. A., Baldocchi D. D. What is global photosynthesis? History, uncertainties and opportunities. Remote Sens. Environ. 223, 95-114 (2019).

43. Myneni, R. B., Williams D. L. On the relationship between FAPAR and NDVI. Remote Sens. Environ. 49, 200-211 (1994).

44. Forkel, M. et al. Codominant water control on global interannual variability and trends in land surface phenology and greenness. Glob. Chang. Biol. 21, 3414-3435 (2015).

45. He, J. et al. The first high-resolution meteorological forcing dataset for land process studies over China. Sci. Data. 7, 25 (2020).

46. Meek, D. W. et al. A Generalized Relationship between Photosynthetically Active Radiation and Solar Radiation. Agron. J. 76, 939-945 (1984).

47. Viovy, N. CRUNCEP Version 7 - Atmospheric Forcing Data for the Community Land Model.) (2018).

48. Peng, Y. et al. Global climate and nutrient controls of photosynthetic capacity. Commun. Biol. 4, 462 (2021).

49. Turner, D. P. et al. Assessing FPAR source and parameter optimization scheme in application of a diagnostic carbon flux model. Remote Sens. Environ. 113, 1529-1539 (2009).

50. Yang, Y., Donohue R. J., McVicar T. R., Roderick M. L. An analytical model for relating global terrestrial carbon assimilation with climate and surface conditions using a rate limitation framework. Geophys. Res. Lett. 42, 9825-9835 (2015).

51. Yang, J., Medlyn B. E., De Kauwe M. G., Duursma R. A. Applying the Concept of Ecohydrological Equilibrium to Predict Steady State Leaf Area Index. J. Adv. Model. Earth Syst. 10, 1740-1758 (2018).

52. Wang, H. et al. Towards a universal model for carbon dioxide uptake by plants. Nat. Plants $\mathbf{3}$, 734-741 (2017).

53. Stocker, B. D. et al. P-model v1.0: an optimality-based light use efficiency model for simulating ecosystem gross primary production. Geosci. Model Dev. 13, 1545-1581 (2020).

54. Cai, W., Prentice I. C. Recent trends in gross primary production and their drivers: analysis and modelling at flux-site and global scales. Environ. Res. Lett. 15, 124050 (2020). 
55. Wang, H. et al. Photosynthetic responses to altitude: an explanation based on optimality principles. New Phytol. 213, 976-982 (2017).

56. Farquhar, G. D., von Caemmerer S., Berry J. A. A biochemical model of photosynthetic $\mathrm{CO}_{2}$ assimilation in leaves of C 3 species. Planta 149, 78-90 (1980). theoretical framework for plant functional ecology. Ecol. Lett. 17, 82-91 (2014).

58. Monsi, M. Uber den Lichtfaktor in den Pflanzen-gesellschaften und seine Bedeutung fur die Stoffproduktion. Jap. Journ. Bot. 14, 22-52 (1953).

59. Ma, H. et al. The global distribution and environmental drivers of aboveground versus belowground plant biomass. Nat. Ecol. Evol. 5, 1110-1122 (2021).

60. Qiao, S., Wang H., Prentice I. C., Harrison S. P. Extending a first-principles primary production model to predict wheat yields. Agric. For. Meteorol. 287, 107932 (2020).

61. Qiao, S., Wang H., Prentice I. C., Harrison S. P. Optimality-based modelling of climate impacts on global potential wheat yield. Environ. Res. Lett. 16, 114013 (2021).

62. Tan, S., Wang H., Prentice I. C., Yang K. Land-surface evapotranspiration derived from a firstprinciples primary production model. Environ. Res. Lett. 16, 104047 (2021).

63. Xia, J. et al. Estimates of grassland biomass and turnover time on the Tibetan Plateau. Environ. Res. Lett. 13, 1-12 (2018). 


\section{Supplementary Files}

This is a list of supplementary files associated with this preprint. Click to download.

- Supplementary20211225.docx 